\title{
Emme manifoldu malzeme seçiminde bilgisayar destekli yazılım kullanılması
}

\author{
Using computer-aided software for intake manifold material selection
}

\author{
Şükran EFE*1,a, Murat ÇOLAK ${ }^{2, b}$ \\ ${ }^{1}$ Atatürk Üniversitesi Mühendislik Fakültesi Makine Mühendisliği Bölümü, 25240, Erzurum / Türkiye \\ ${ }^{2}$ Bayburt Üniversitesi Mühendislik Fakültesi Makine Mühendisliği Bölümü, 69000, Bayburt / Türkiye
}

• Geliş tarihi / Received: 07.12.2020 • Düzeltilerek geliş tarihi / Received in revised form: 08.05.2021 • Kabul tarihi / Accepted: 06.06.2021

\section{Öz}

Dört zamanlı bir içten yanmalı motor 30 000'den fazla parçadan oluşmaktadır. Bu parçalar birçoğu, motorlardaki çalışma prensipleri nedeniyle yüksek sıcaklık, yüksek basınç, yüksek gerilmelere maruz kalabilmektedir. Motorlarda gerçekleşen çevrimlerin yüksek motor performansı ve yüksek enerji verimliliği için kararlı yapıda olması gerekmektedir. Bir çevrimin ortalama 0.025 saniyede tamamlandığı düşünülecek olursa, kullanılan çoğu motor parçasının üretimi için gerekli malzeme seçiminin, sistem kararlığı açısından ne kadar önemli olduğu görülmektedir. Malzeme seçiminde parçalarda kullanılan malzemelerin yapısal özellikleri kadar kuvvet, basınç, sıcaklık gibi çalışma şartları altındaki davranışlarının da iyi bilinmesi gerekmektedir. Malzeme seçimini önemli kılan bir diğer hususta ekonomikliktir. Malzeme özelliklerinin her geçen gün iyileştirildiği günümüzde, malzeme seçimi için bilgisayar destekli yazılım programları kullanılmaktadır. $\mathrm{Bu}$ çalışmada birçok bilgisayar destekli yazılım programına rağmen malzemelerin teknik özelikleriyle birlikte malzemenin ekonomikliğini de analiz eden CES Selector isimli bilgisayar destekli malzeme seçim programı kullanılmıştır. Bu program kullanılarak, motor performansına ve yanma verimine direk etki eden emme manifoldunun malzeme seçimi yapılmıştır. Sonuç olarak kokil kalıba dökülen, T6 1 ssıl işlemi yapılmış A356 alüminyum alaşımının en uygun malzeme olduğuna karar verilmiştir.

Anahtar kelimeler: Bilgisayar destekli malzeme seçimi, CES selector yazılımı, Emme manifoldu

\begin{abstract}
A four-stroke internal combustion engine consists of more than 30000 parts. Many of these parts can be exposed to high temperatures, high pressure and high stresses due to the operating conditions of engines. In material selection, it is necessary to know the structural properties of the materials used in the parts as well as their behaviour under operating conditions such as force, pressure, temperature. Considering that a cycle is completed in 0.025 seconds on average, it is seen how important the material selection for the production of most engine parts used is in terms of system stability. Another important factor is economy in material selection. Nowadays, material properties are improving day by day, computer-aided software programs are used for material selection. In this study, a computer-aided material selection program named CES Selector, which analyses the technical properties of the materials as well as the economics of the material, was used despite many computer-aided software programs. By using CES Selector program, material selection of the intake manifold, which directly affects engine performance and combustion efficiency, was made. As a result, it was decided that A356 aluminium alloy cast into gravity mold and T6 heat treated was the most suitable material.
\end{abstract}

Keywords: Computer-aided material selection, CES celector software, Intake manifold

\footnotetext{
*a Şükran EFE; sukran.efe@atauni.edu.tr; Tel: (0442) 231 4632, orcid.org/0000-0002-4033-6786

${ }^{\mathrm{b}}$ orcid.org/0000-0002-8255-5987
} 


\section{Giriş}

Artan dünya nüfusu ve gelişen teknolojiyle bilirlikte enerji tüketimi de hızla artmaktadır. Hem kullanılan enerji kaynaklarının tüketim hızını azaltmak hem de bu kaynakların kullanımıyla doğaya salınan zararlı gazların çevredeki tahribatını engellemek amacıyla enerjinin verimli kullanılmasını ön plana çıkaran uluslararası sözleşmeler bulunmaktadır (IEA,2020).

2020 OECD Enerji Raporuna göre; dünyada tüketilen enerjinin miktarı diğer sektörlerde genel olarak aynı iken ulaşım da her geçen gün artmakta ve bu rakam 1971 yılında \%23 iken 2015 yılında \%29 a yükselerek, yükselişini sürdürmektedir (UNFCCC, 2008). İçten yanmalı motorlar ulaşımda yaygın olarak kullanıldığı için enerji tüketiminde de önemli bir parametredir ve yapılan uluslararası kısıtlamaların temelini teşkil etmektedir. Bir motorun tükettiği enerjiyi azaltmanın en iyi yolu, harcadığ 1 enerjiyi verimli bir şekilde kullanmasını sağlamaktadır. Tam bu noktada motor tasarımın önemi ön plana çıkmakta ve literatürde yapılan çalışmalarda tasarımın enerji üzerindeki etkisi incelenmektedir (Vijaya Kumar vd. 2020; Chandekar and Debnath, 2020; Jain et al., 2021). Genel anlamda tasarım; temel bir ihtiyacin karşılanması amaciyla problemin çözümüne yönelik analiz, sentez, malzeme seçimi, ölçme ve kontrol yöntemlerin harmanlanmasidır. Mühendislikte tasarımı ise herhangi teknik bir sistemin fiziksel prensiplerin saptanmas1, bu prensipleri sağlayan elemanların seçimi, bunların montaj ve parça resimlerinin hazırlanmasına kadar geçen bütün faaliyetleri kapsamaktadır (Ashby et al., 2007; Findik vd, 2018;). Bu nedenle mühendislik tasarımında ilk ve en önemli aşama; parçanın kullanım amacına uygun özellikte malzeme seçimi olmaktadır (Sapuan, 2001; Sapuan et al., 2002; Amen and Vomacka, 2001).

Dört zaman bir içten yanmalı motorda (IYYM) (B ve C segmenti için) 30000 'den fazla parça vardır (Simav ve Ustabaş, 2017). Kritik önemdeki birçok parça, motorlardaki çalışma koşulları nedeniyle yüksek sıcaklık, yüksek basınç, yüksek gerilmelere maruz kalabilmektedir. Çevrim prensibiyle çalışan tüm sistemlerde olduğu gibi, motorlarda da çevrim kararlılığ1; sistem çalışması, performans ve verimlilik açısından çok önemlidir. Çevrim kararlılığı için her çevrimin aynı başlangıç şartlarında yeniden başlatılması gerekmektedir. İYM'daki çevrimlerin başlangıç şartlarının atmosfer şartlarına yakın olmasına rağmen çalışma şartlarının ortalama $1000^{\circ} \mathrm{C}$ ve $3 \mathrm{MP}$ gibi yüksek değerlerde olması ve daha da önemlisi çevrimin ortalama 0.025 saniye kadar kısa sürede gerçekleşmesi, İYM da çevrim kararlılığını sağlamanın ne kadar zor olduğunu göstermektedir. $\mathrm{Bu}$ kararlılığı sağlamak için dikkat edilmesi gereken husus doğru tasarım için uygun malzeme seçimidir (Ferguson and Kirkpatrick, 2001; Safgönül vd., 2008).

Motorlarda kullanılan birçok parça kararlı çalışma şartlarında maruz kaldığ 1 1sı nedeniyle belirli bir miktar 1sınır (Şekil 1) ve üretildiği malzemeye göre de 1 sıl genleşmeye maruz kalır. Çevrimin ilk başlangıç noktası olan atmosfer şartlarındaki dolgunun (hava veya yakıt-hava karışımı) silindir içerisine alınmasından sonra, dolgunun sıcaklığı emme manifoldunun şartlarına (tasarım, sürtünme, yüzey sicaklığı, ortam sicaklığı vb.) bağlı olarak $60^{\circ} \mathrm{C}$ ye kadar artmaktadır (Pulkraberk, 1997).

Emme manifoldu, dağıtıcı olarak isimlendirilen borular içinden dolguyu her bir silindire eşit olarak aktaran, sistem verimine direk etki eden motor parçasıdır. Kullanılan motor tasarımına bağlı olarak, piyasada farklı şekil ve malzemelerden üretilmiş birçok emme manifoldu bulunmaktadır (Şekil 2).

Kararlı haldeki bir motorda emme manifoldunun çeper sıcaklı̆ğ, içerisinden akan dolgudan daha fazladır. Bunun sebebi, manifold çeperinin hem motor bloğu ile temasından kaynaklan 1sı iletimi hem de sicak motor parçalarından kaynaklanan 1s1 taşınımıdır. Emme manifoldunun 1sınmasıyla artan dolgu sıcaklığ ; (1) yakıtın daha erken buharlaşarak hava ile daha homojen bir karışım elde edilmesine, (2) dolgudaki havanın yoğunluğunun azalmasına ve yakıtın buharlaşmasına (buharlaşan yakıt molekülleri dolgudaki hava moleküllerinin yerini alır) neden olduğu için motorun volümetrik veriminin düşmesine, (3) silindir içine alınan dolgu sicaklığının artmasına ve artan dolgu sıcaklığı nedeniyle çevrimdeki diğer sıcaklıkların artarak vuruntu meylini artırmasina sebep olmaktadır (Heywood, 1988).

Motor performansının ve veriminin direk etkilendiği emme manifoldu tasarımında malzeme seçimi yapılırken, çalışma şartları azami önemde dikkate alınmalıdır. Genel olarak çalışma şartları incelendiğinde; (1) soğuk iklim şartlarında (ortalama $-30^{\circ} \mathrm{C}$ ) ki bir aracin emme manifoldu motorun çalışmasıyla kararlı hale (yaklaşık $60^{\circ} \mathrm{C}$ ) gelerek yaklaşık 30 dakikada $80-100^{\circ} \mathrm{C}$ de sicaklık değişimine maruz kalacağ 1 için bu sicaklık değişimde deformasyona uğramadan, oluşacak gerilmeleri absorbe edebilecek özelliğine sahip olmalı, (2) soğuk iklim şartlarında motorun ilk 
çalışmasını kolaylaştırmak amacıyla dolguyu 1sitabilecek tasarımda imal edilebilmeli, (3) motorun kararlı çalışma şartlarında ısınması nedeniyle şekilsel deformasyonu engellemek amacıyla uygun isıl genleşme katsayısına ve dolgunun aşırı 1sınmasını engelleyerek homojen bir karışım elde etmek amacıyla da yüksek 1s1 iletkenliğine sahip olmalı, (4) konumu nedeniyle olağan dışı durumlarda aşırı ısıya maruz kalma ihtimali göz önüne alındığında, yapısal deformasyonları en aza indirmek amaciyla uygun genleşme katsayısına sahip olmalı, (5) yüksek iç yüzey pürüzlülügü, sürtünmeyi artırarak dolgunun hızını düşmesine, basınç ve sıcaklık artışına neden olacağı için uygun yüzey pürüzlülük değeri için uygun üretim yöntemi belirlenmeli, (6) enerji verimliliğini artırmak amaciyla maliyet ve sürdürülebilirlik de göz önüne alınarak en hafif malzemenin seçimine, (7) hassas yüzey pürüzlülüğü ve hassas geometrik yapısı nedeniyle üretim yöntemi göz önüne alınarak uygun malzeme seçimi yapılmasına, (8) dağıtıcılarda homojen akışı sağlamak ve yüzey sürtünmelerini minimuma indirmek amacıyla tasarımda keskin dağıtıcı ayrımlarından, keskin köşelerden kaçınılmalı, (9) minimum maliyet maksimum performans göz önüne alınarak yeterli hacim belirleme, (10) atmosfer havasıyla sürekli teması nedeniyle yüksek korozyon direncine sahip olması istenilmektedir.

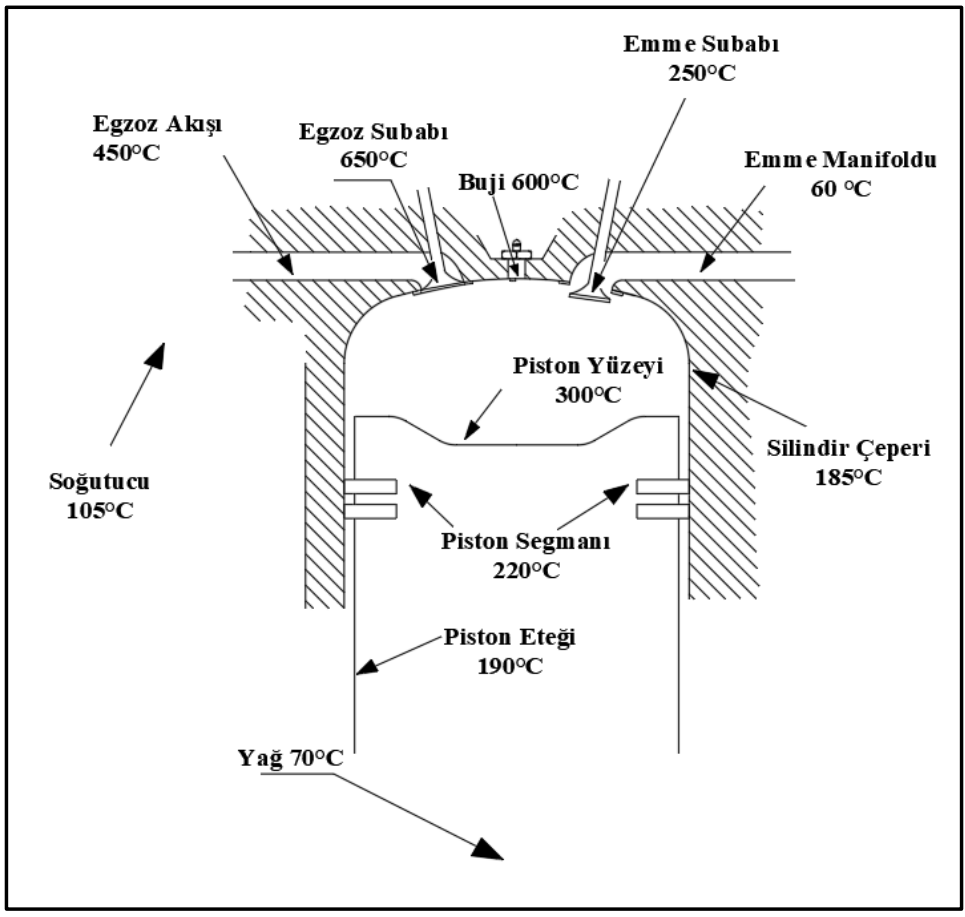

Şekil 1. Normal kararlı şartlarda çalışan bir benzinli motorun tipik sıcaklık değerleri (Pulkraberk, 1997).

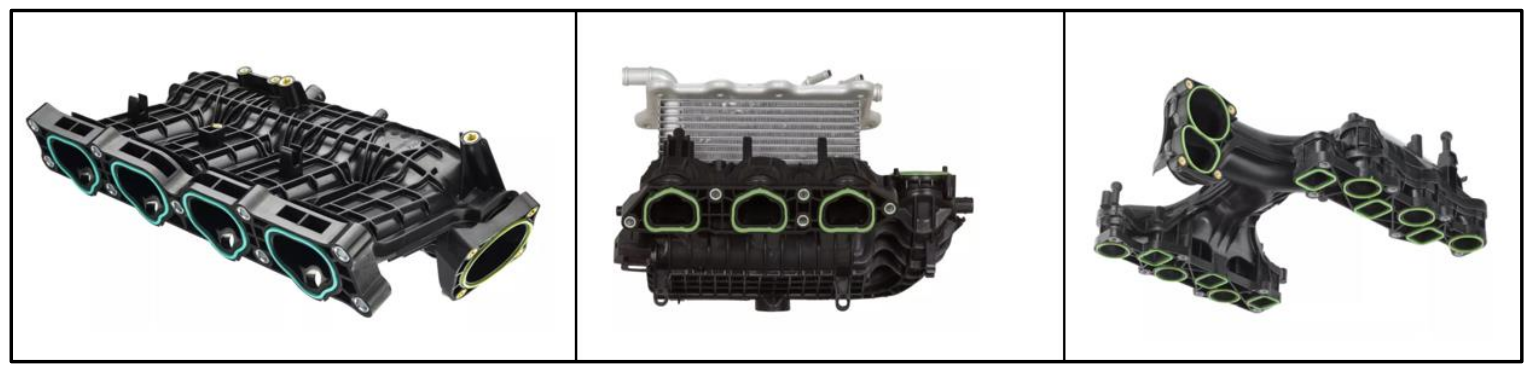

Şekil 2. Farklı tasarımlı emme manifold örnekleri (Röchling Automotive, 2021)

İnşaat, mekanik, elektronik, bilişim gibi günümüzdeki bütün mühendislik sistemlerinde performans ve ekonomikliği sağlamak amaciyla kullanılan metalleri, seramikleri, camları, polimerleri, elastomerleri ve kompozitleri içeren geniş bir malzeme envanteri bulunmaktadır. $\mathrm{Bu}$ temel malzemeler içerisine alaşımlar ve kaplamalar gibi yeni geliştirilen malzemeler de ilave edildiğinde, ürün yelpazesi genişlemekle birlikte uygun malzeme seçimi de giderek kompleks hale gelmektedir (Ashby et al., 2004; Bovea and Vidal, 2004; Cebon and Ashby, 2005; Giudice et al., 
2005; Goldsberry, 2006; Jalham, 2006; Balakrishna et al., 2007; Karana et al., 2008; Ramalhete et al., 2010). Özellikle bir parçanın başlangıç ve çalışma şartlarına göre değişen malzeme özelliklerini (moleküler yapı, yoğunluk, termal davranış, mekanik özellikler, gerilme davranışlarını vb.) bir araya getirerek analiz edebilen bilgisayar destekli analiz sistemlerine ihtiyaç duyulmaktadır. $\mathrm{Bu}$ sistemler, birçok malzemenin birçok özelliğini depolayarak, bilgisayar ortamında analiz edilmesine imkân tanımakta, tasarımcıya geniş bir yelpazeden hızlı ve güvenilir sonuç sunarak en uygun malzeme seçimini sağlamaktadır (Askeland, 2009; Shackelford, 2009). Malzemenin birim maliyeti, başlangıç özelikleri, çalışma şartlarındaki özellikler, işlenebilirlik, sürdürülebilirlik, imalat ve montaj kolaylığı, garanti ve servis maliyetleri gibi birçok özellik birlikte değerlendirildiğinde bir parça için malzeme seçiminin ne kadar karmaşık ve zor olduğu ortaya çıkmaktadır. Literatürde malzeme seçimi için farklı malzeme seçim yöntemlerini kullanan birçok çalışma bulunmaktadır. CES Selector isimli bilgisayar destekli malzeme seçim programı literatürde kullanılan birçok programdan farklı olarak; malzemenin mekanik, fiziksel, kimyasal özelliklerin yanı sıra maliyet ve şekillendirilebilme özelliğini de göz önüne alarak seçim yapmaktadır. Literatürde bu programın kullanılarak malzeme seçiminin başarılı bir şekilde yapıldığı çalışmalar mevcuttur (Findık vd., 2015; Sensoy vd., 2019).

Bu çalışmada Ashby ve Granta Design tarafından geliştirilen CES Selector yazılımı kullanılarak motor performansina ve yanma verimine direk etki eden emme manifoldu için malzeme seçimi yapılmıştır. Yapılan çalışma ile CES Selector programının hem çok geniş olan ürün yelpazesinden faydalanmak hem de elde edilen sonuçları günümüzde kullanılan emme manifold malzemeleriyle karşılaştırmak amaçlanmıştır.

\section{Materyal ve metot}

Bilgisayar destekli malzeme seçim programı CES Selector yazılımının arayüzü oldukça sade ve kullanışlıdır. Hem malzeme yelpazesinin geniş olması hem de malzeme seçim özeliklerine maliyetin de eklenmiş olması, programın diğer programlara göre üstün özelliğidir. Ayrıca programda malzeme seçimi için farklı yöntemler bulunmaktadır. Bunlardan en yaygın kullanılan metotları; malzeme veri tabanından ilgili ürün için arama yaptırmak, istenen özellik karşılaştırma grafikleri üzerinde seçim yapmak ve belirlenen seçim kriterlerine uygun malzemelerin eleme yöntemiyle belirlenmesi ve ağırlıklandırılmış özelliklere bağlı seçim yapmak vb. olarak sıralamak mümkündür. Ashby Diyagramları adı verilen ve iki özellik arasında çizilen grafiklerle mevcut iki özellik için malzeme gruplarının nerede yer aldığını görmek mümkün olmaktadır. Şekil 3'te akma dayanımına karşı yoğunluk grafiği örnek olarak verilmiştir. Grafiklerde malzeme grupları farklı renklerde görülmektedir. Bu grafiklerden istenen özelliklerdeki malzeme grupları belirlenebilir ve malzeme gruplarının belirlenen özelliklerdeki değerleri tespit edilebilir. $\mathrm{Bu}$ aşamada grafikler üzerinde istenirse malzeme gruplarından seçim yapılabilir ya da bu malzeme grubu üzerinde odaklanılarak daha hassas bir seçim ile işleme de devam edilebilir.

$\mathrm{Bu}$ çalışmada belirlenen sınır değerlerine bağlı seçim işlemi prosedürü kullanılacaktır. Bunun için ilk olarak Selection sekmesi, sonrasında malzeme veri tabanı belirlenir. Belirlenen malzeme tabanı verileri kullanılarak özelliklere bağlı olarak grafikler veya belirli sınır şartları girilerek malzeme seçimi işlemine devam edilir. Sonrasında, malzemenin gerekli sınır değerlerini yazılımda limit kısmından belirleyerek seçim işlemine devam edilir. Malzeme veri taban1; fiyat, fiziksel özellikler, mekanik özellikler, termal özellikler, işlenebilirlik gibi gerekli olabilecek birçok alt başlıklarından oluşmaktadır. $\mathrm{Bu}$ kısımda malzemenin kullanılacağı yer göz önüne alınarak istenilen bütün minimum ve maksimum sinır şartları değerleri belirlenerek seçim yapılır ve buna göre alternatif malzemeler sıralanır. Verilen sinır şartlarına göre alternatif malzemelerden ağırlıklandırılmış özelliklerine bağlı olarak karşılaştırma yapılarak malzeme seçimi yapılır.

Emme manifoldu malzemesi için gerekli özelliklerin değerlendirilmesi ve mevcut malzemelerin tamamının incelenmesi için alternatif malzeme gruplarının hepsini seçilmiştir. Seçim için uygun veri tabanı seçildikten sonra seçim işlemine malzemeden istenen diğer özelliklere ait minimum ve maksimum sınır değerler girilerek devam edilecektir. Malzeme için belirlenen ve seçim için kullanılan sınır şartı değerleri Tablo 1'de verilmiştir. Sınır değerlerin belirlenmesinde, günümüzde piyasada kullanılan malzemeler referans alınarak, en uygun özellikte malzeme seçimine imkân verecek şekilde tanımlama yapılmıştır. Böylece gerekli özellikler için yeni malzemeleri de kapsayacak şekilde alternatif malzemelerin karşılaştırılması hedeflenmiştir (Birtok-Băneasă et al., 2019; Çetin ve Sayer, 2019; Azo Metarials, 2021; Epsan, 2021). 


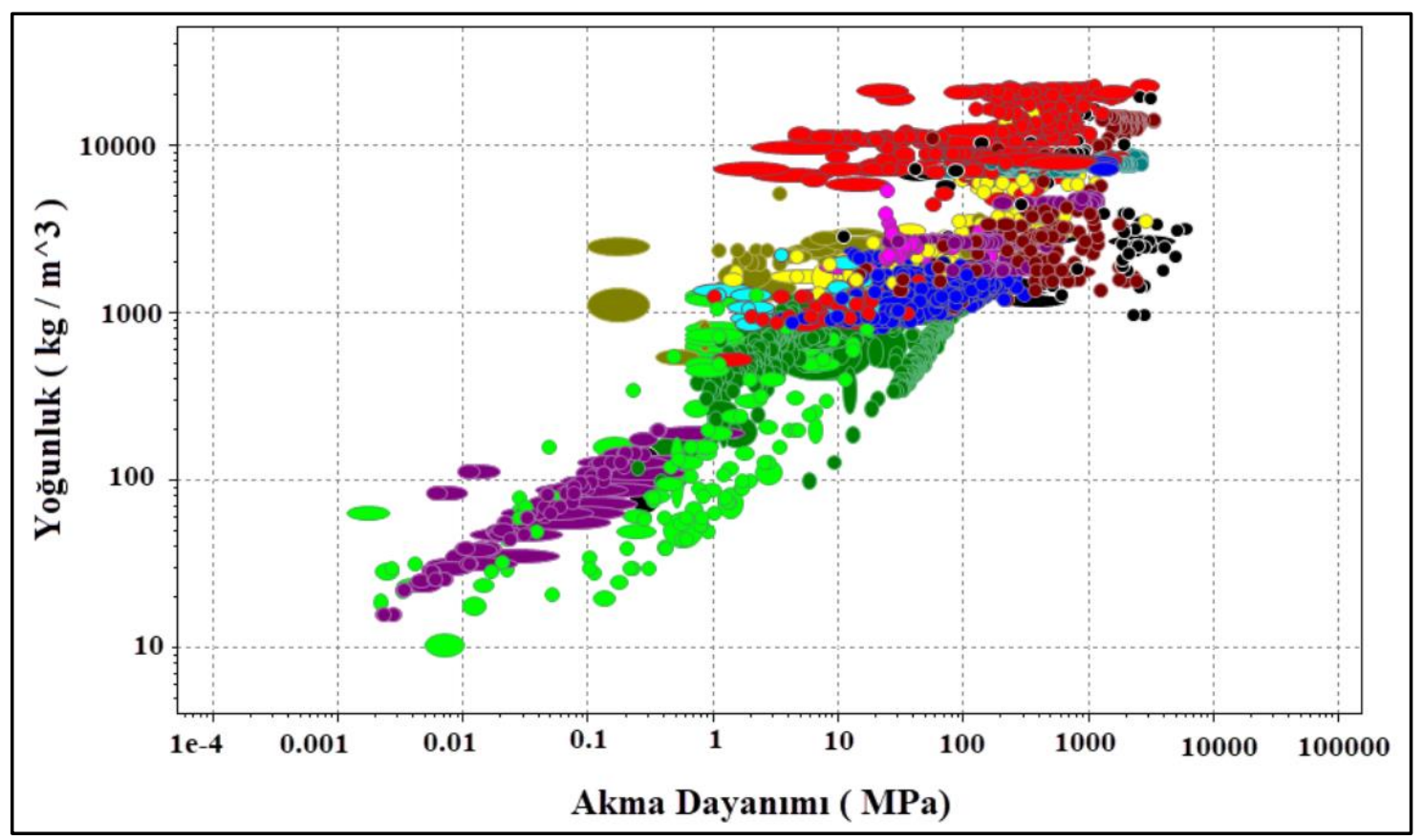

Şekil 3. Akma dayanıma bağlı yoğunluk özelliklerinin karşılaştırılması

Tablo 1. Emme manifoldu malzemesi seçiminde kullanılan özellik ve sınır şartı değerleri

\begin{tabular}{lc}
\hline Nitelik (Özellik) & Sınır Değerler \\
\hline Fiyat $(\mathrm{TRY} / \mathrm{kg})$ & $\leq 20$ \\
Yoğunluk $\left(\mathrm{kg} / \mathrm{m}^{3}\right)$ & $\leq 4000$ \\
Akma Dayanımı (Elastik Sınır) $(\mathrm{MPa})$ & $\geq 100$ \\
Kırılma Tokluğu $(\mathrm{MPa} . \sqrt{\mathrm{m}})$ & $\geq 5$ \\
Termal Genleşme Katsayısı $\left(\mu \mathrm{strain} /{ }^{\circ} \mathrm{C}\right)$ & $\leq 25$ \\
Metal Döküm & Uygun \\
\hline
\end{tabular}

Malzeme özellikleri için istenirse değer aralığ1 belirlenebileceği gibi, Tablo 1'de görüldüğü gibi gerekli minimum ya da maksimum değerlerde yazilabilir.

\section{Bulgular}

Programa tanımlanan Tablo 1'deki kriterler doğrultusunda, program tarafindan 43 adet malzemenin uygun olduğu tespit edilmiştir. $\mathrm{Bu} 43$ malzeme incelendiği zaman; genel olarak alüminyum ve magnezyum döküm alaşımlarından oluştuğu görülmektedir. Programa üretim yöntemi olarak döküm tanımlandığı için, sunulan malzeme listesinde kum kalıp, kokil kalıp döküm yöntemi ile üretilen alternatif formlar veya bu formların isıl işlem ile değişkenlik gösterdiği farklı malzeme formları bulunmaktadır. Örneğin; A356 alaşımı için malzeme veri tabanında üretim yöntemine bağlı olarak altı farklı alternatif ürün ve özellikleri sunulmuştur. Tablo 2'de A356 alaşımına ait malzeme özellikleri karşılaştırma olarak sunulmuştur.

Tablo 2'de verilen değerler incelendiğinde; tüm malzemelerin istenilen sınır şartlarına sahip ve birbirine yakın değerlere sahip olduğu görülmektedir. $\mathrm{Bu}$ değerlerin, kokil kalıba döküldükten sonra T6 1sıl işlemi uygulanan A356 alüminyum döküm alaşımının diğer alaşımlara nazaran akma dayanımı açısından daha iyi olduğu tespit edilmiştir. Ancak firma üretim prosesi ve diğer özelliklere bağlı olarak diğer yöntemler ile üretilen malzemelerinde seçimi konusunda emme manifoldu malzeme seçimi için uygun bir alternatif olacağı da unutulmamalıdır.

Belirlenen limit değerlerine bağlı kalarak, aynı üretim prosesinde alaşım bazlı özelliklerin karşılaş̧ırılması amacıyla alüminyum alaşımlı ve magnezyum alaşımlı alternatifler incelenmiş, sırasıyla Tablo 3'de ve Tablo 4'de sunulmuştur. 
Tablo 2. A356 malzemelerin üretim yöntemine bağlı karşılaştırılması.

\begin{tabular}{|c|c|c|c|c|c|c|}
\hline Özellik & $\begin{array}{c}\text { Alüminyum } \\
\text { A356.0 } \\
\text { Kokil Kalıp } \\
\text { T6 }\end{array}$ & $\begin{array}{c}\text { Alüminyum } \\
\text { 356.0 } \\
\text { Hassas } \\
\text { Döküm } \\
\text { T6 }\end{array}$ & $\begin{array}{c}\text { Alüminyum } \\
\text { 356.0 } \\
\text { Kokil Kalıp } \\
\text { T6 }\end{array}$ & $\begin{array}{c}\text { Alüminyum } \\
\text { 356.0 } \\
\text { Kum Döküm } \\
\text { F }\end{array}$ & $\begin{array}{c}\text { Alüminyum } \\
\text { 356.0 } \\
\text { Kum Döküm } \\
\text { T6 }\end{array}$ & $\begin{array}{c}\text { Alüminyum } \\
\text { A356.0 } \\
\text { Kum Döküm } \\
\text { T6 }\end{array}$ \\
\hline Fiyat $[€ / \mathrm{kg}]$ & $6.4-7.35$ & $6.4-7.35$ & $6.4-7.35$ & $6.4-7.35$ & $6.4-7.35$ & $6.4-7.35$ \\
\hline Yoğunluk $\left[\mathrm{kg} / \mathrm{m}^{3}\right]$ & $2660-2710$ & $2660-2710$ & $2660-2710$ & $2660-2710$ & $2660-2710$ & $2660-2710$ \\
\hline Akma Muk. [MPa] & $241-263$ & $105-116$ & $164-182$ & $118-130$ & $146-162$ & $197-213$ \\
\hline Kopma Muk. [MPa. $\sqrt{ } \mathrm{m}]$ & $35-40$ & $19-21$ & $19-21$ & $28-32.2$ & $19-21$ & $35-40$ \\
\hline$\left[\mu\right.$ strain $\left./{ }^{\circ} \mathrm{C}\right]$ & $20.7-22.4$ & 20.6-22.4 & $20.6-22.4$ & $20.6-22.4$ & $20.6-22.4$ & $20.7-22.4$ \\
\hline Metal Döküm & Mükemmel & Mükemmel & Mükemmel & Mükemmel & Mükemmel & Mükemmel \\
\hline
\end{tabular}

Tablo 3. Emme manifoldu için alüminyum alaşımı malzeme özelliklerinin karşılaştırılması

\begin{tabular}{|c|c|c|c|c|c|c|}
\hline Özellik & $\begin{array}{c}\text { Alüminyum } \\
\text { A356.0 } \\
\text { Kokil Kalıp } \\
\text { T6 }\end{array}$ & $\begin{array}{c}\text { Alüminyum } \\
319.0 \\
\text { Kokil Kalıp } \\
\text { T6 }\end{array}$ & $\begin{array}{c}\text { Alüminyum } \\
\text { 333.0 } \\
\text { Kokil Kalıp } \\
\text { T6 }\end{array}$ & $\begin{array}{c}\text { Alüminyum } \\
336.0 \\
\text { Kokil Kalıp } \\
\text { T65 }\end{array}$ & $\begin{array}{c}\text { Alüminyum } \\
355.0 \\
\text { Kokil Kalıp } \\
\text { T6 }\end{array}$ & $\begin{array}{c}\text { Alüminyum } \\
\text { A357.0 } \\
\text { Kokil Kalıp } \\
\text { T6 }\end{array}$ \\
\hline Fiyat $[€ / \mathrm{kg}]$ & $6.4-7.35$ & $6.82-7.8$ & $6.9-7.94$ & $7.74-8.91$ & $6.48-7.43$ & $7.52-8.72$ \\
\hline Yoğunluk $[\mathrm{kg} / \mathrm{m} 3]$ & $2660-2710$ & $2770-2820$ & $2740-2800$ & $2690-2740$ & $2680-2740$ & $2650-2710$ \\
\hline Akma Muk.[MPa] & $241-263$ & $157-173$ & $197-217$ & $281-311$ & $165-182$ & $244-263$ \\
\hline Kopma Muk. [MPa. $\sqrt{ }$ m] & $35-40$ & $20.7-23.9$ & $19.4-22.3$ & $16.5-18.6$ & $21.2-24.4$ & $24.6-28.8$ \\
\hline Is1l Gen. Kats. $\left[\mu\right.$ strain $\left./{ }^{\circ} \mathrm{C}\right]$ & $20.7-22.4$ & $21.1-22.1$ & $20.2-21.2$ & 18.4-19.4 & 21.9-22.9 & $21.3-22.1$ \\
\hline Metal Döküm & Mükemmel & Uygun & Mükemmel & Uygun & Mükemmel & Mükemmel \\
\hline
\end{tabular}

Tablo 4. Emme manifoldu için magnezyum alaşımı malzeme özelliklerinin karşılaştırılması

\begin{tabular}{lccccc}
\hline Özellik & $\begin{array}{c}\text { Magnezyum } \\
\text { WE54A } \\
\text { Döküm }\end{array}$ & $\begin{array}{c}\text { Magnezyum } \\
\text { Elektron 21 }\end{array}$ & $\begin{array}{c}\text { Magnezyum } \\
\text { AZ91D } \\
\text { Döküm }\end{array}$ & $\begin{array}{c}\text { Magnezyum } \\
\text { AZ81A } \\
\text { Döküm }\end{array}$ & $\begin{array}{c}\text { Magnezyum } \\
\text { AM60B } \\
\text { Döküm }\end{array}$ \\
\hline Fiyat $[€ / \mathrm{kg}]$ & $16.3-17.1$ & $15.1-16.1$ & $8.41-8.8$ & $8.44-8.83$ & $8.44-8.83$ \\
Yoğunluk $[\mathrm{kg} / \mathrm{m} 3]$ & $1850-1860$ & $1810-1830$ & $1800-1820$ & $1810-1820$ & $1770-1790$ \\
Akma Muk. $[\mathrm{MPa}]$ & $200-210$ & $145-178$ & $142-168$ & $145-155$ & $130-143$ \\
Kopma Muk. $[\mathrm{MPa} . \sqrt{ } \mathrm{m}]$ & $14.3-14.4$ & $14.5-15.5$ & $12-14$ & $14-15$ & $15-16$ \\
Is1l Gen. Kats. $\left[\mu \mathrm{strain} /{ }^{\circ} \mathrm{C}\right]$ & $24.6-24.7$ & $24.6-26$ & $24.3-25.6$ & $25-25.1$ & $25-26.3$ \\
Metal Döküm & Mükemmel & Mükemmel & Mükemmel & Mükemmel & Mükemmel \\
\hline
\end{tabular}

\section{Değerlendirme ve sonuçlar}

Emme manifoldu üretiminde yaygın olarak alüminyum ve magnezyum alaşımlarının kullanıldı ğı bilinmektedir. Bunun yanı sıra nadiren de olsa polyamid malzemelerin denendiği bilinmektedir (Hickman and Schumacher, 2005; Çetin ve Sayer, 2019). Emme manifoldunda alüminyum tercih edilmesinin nedeni; iyi bir $1 \mathrm{~s} 1$ transferi sağlaması, kolay şekil verilebilir olması ve hafif olmasidir (Chen and Jiang, 2008). Magnezyum ise düşük ağırlıklı ve yüksek dayanımlı malzeme üretimi için alternatifler arasında yer almaktadır. Magnezyum, alüminyumdan $\% 35$, çelikten ise $\% 78$ daha hafif bir metaldir. Bunun sonucunda magnezyum ve alaşımları hafifliğin önem arz ettiği kara ve hava taşıtlarında kullanım bulduğu bilinmektedir (Kandemir ve Can, 2003).

Malzeme seçimi için bilgisayar destekli yazılımda kullanıldığında sürekli gelişen alternatif malzemelerin takibi ve halihazırdaki malzemeler hakkında bilgi sahibi olunması mümkün olup ve kullanıcının çok yoğun bilgisine ihtiyaç yoktur. Bu sebeple malzeme seçimi için bilgisayar destekli yazılım kullanılmasının faydalı olduğu düşünülmektedir.

CES Selector Programı kullanılarak malzeme seçiminin yapıldı $\mathrm{g} 1$ bu çalışmada, emme manifoldu için malzeme seçimi yapılıştır. Çalışma şartları göz önünde bulundurularak belirlenen emme manifoldunun önemli özellikleri belirlenerek, ilgili özellik için sınır değerleri tanımlanmıştır. Daha 
sonra bu değerler programda tanımlanarak, ilgili malzeme seçimi yapılmıştır. Malzeme seçim metodu olarak, ön eleme, özelliklerin değerlendirilmesi ve ağırlıklı özelliklere bağlı olarak karar verme, limit değerlerin değerlendirilmesi ve optimum özellik maliyet ve şekillendirilebilme kriterlerine bağlı seçim aşamaları kullanılmıştır.

Malzeme seçimi işleminde aynı alaşımın farklı üretim şartlarına bağlı olarak alternatiflerinin mevcut olduğu ve döküm yöntemi, kalıp malzemesi ve 1sıl işleme bağlı olarak değişkenlik gösterdiği gözlenmiştir. Malzeme seçimi sonucu olarak; özelliklerinin birbirine yakın olmas1 nedeniyle alüminyum veya magnezyum alaşımı belirlenmiştir. $\mathrm{Bu}$ aşamada hassas bir seçim ve ağırlıklandırılmış malzeme seçimi metodunda olduğu gibi daha önemli olan özelliğe göre malzeme seçimi yapılmasının uygun olacağ anlaşılmıştır. Alüminyum alaşımları incelendiğinde akma dayanımı açısından en iyi malzemenin kokil kalıba dökülen T65 1sıl işlemi sonucu A336 alüminyum alaşımı olduğu, ancak bu malzemenin kırıma tokluğunun nispeten düşük ve fiyat olarak alternatiflerinden daha yüksek olduğu gözlenmektedir. Tüm malzeme özellikleri ele alınarak alüminyum malzemeler arasındaki seçimde A356 alüminyum alaşımının avantajlı olduğu düşünülmektedir.

A356 alaşımı için üretim prosesine bağlı özellikler incelendiğinde akma dayanımı açısından kokil kalıba döküldükten sonra T6 1 sıl işlemi uygulanan alaşımının diğer alaşımlara nazaran daha iyi olduğu anlaşılmıştır. Ancak firma üretim prosesi ve diğer özelliklere bağlı olarak diğer yöntemler ile üretilen malzemelerinde kullanılabileceği anlaşılmıştır. Özellikle malzeme yüzeyinden beklenilen düşük pürüzlülük, kokil döküm ile elde edilebilecektir.

Magnezyum alaşımı malzeme alternatifleri incelendiğinde, dayanım açısından en iyi alternatifin WE54A Magnezyum alaşımı olduğu, fiyat hariç diğer özelliklerinin de alternatiflerine nazaran avantajlı olduğu gözlenmektedir. Fiyatı diğer alternatiflerine nazaran yaklaşık iki kat daha fazla olduğu dikkat çekmektedir. Burada malzeme seçiminde kritik bir karar aşaması devreye girmektedir. Önemli olan soru, dayanımdaki bu artış malzeme fiyatının iki kata çıkmasına değecek oranda mıdır? Bu sorunun cevabına bağlı olarak tercih yapılması daha doğru olacaktır. Fiyata bağlı olarak en iyi alternatifinde AZ91D magnezyum alaşımı olduğunu söylemek mümkündür.
Emme manifoldu malzeme seçimi için hafiflik açısından AZ81A Magnezyum döküm alaşımı, üretim açısından A356 alüminyum alaşımının ön plana çıktığı tespit edilmiştir. Tüm özelliklere bağlı olarak yapılan 20değerlendirmelerde emme manifoldu için en iyi malzeme olarak kokil kalıba dökülen, T6 1 ssıl işlemi yapılmış A356 alüminyum alaşımı uygun görülmüştür.

Tüm bu değerlendirmeler ışığında ve belirlenen sınır şartlarına bağlı olarak kalan alternatifler arasında karar aşamasında dikkat edilmesi gereken bir diğer hususta fiyat ile yoğunluk ilişkisi olmalıdır. Tablolarda verilen fiyat değerleri $\mathrm{kg}$ başına birim maliyetlerdir. Dolayısıyla aynı ürünü üretmek için alüminyum tercih edildiğinde ortaya çıkan maliyet toplamda daha fazla olabilecektir. Dolayısıyla AZ81A Magnezyum döküm alaşımı her ne kadar A356 alüminyum döküm alaşımından daha fazla birim maliyete sahip gibi gözükse de üretim sonucunda ürün bazlı fiyatların yaklaşı aynı olacağı da dikkate alınmalıdır. Ancak ülkemiz ve dünyada Magnezyum şekilli parça dökümünde karşılaşılan zorluklar ve çok fazla dökümhane de üretimin bulunmamasindan dolayı Emme manifoldu için en iyi malzeme alternatifinin kokil kalıba dökülen, T6 1sıl işlemi yapılmış A356 alüminyum alaşımı olduğunu söylemek mümkündür. Seçimi yapılan malzeme mevcut literatür ve güncel teknoloji ile de uyumlu olduğu gözlenmiştir.

\section{Kaynaklar}

Amen, R. and Vomacka, P. (2001). Case-based reasoning as a tool for materials selection. Materials and Design 22, 353-358. https://doi.org/10.1016/S0261-3069(00)001059.

Ashby, M. F., Bréchet, Y. J., Cebon, D. and Salvo, L. (2004). Selection strategies for materials and processes. Materials and Design, 25, (1), 51-67, https://doi.org/10.1016/S0261-3069(03)001596.

Ashby, M., Shercliff, H. and Cebon, D. (2007). Materials engineering, science, processing and design. Elsevier.

Askeland, D. (2009). The science and engineering of materials. (5th ed ed.). London: Thomson.

Azo Material, 2021. https://www.azom.com/article.aspx?ArticleID= 2863\#: :text=Mechanical\%20Properties\%20of $\%$ 20Aluminium\&text=It $\% 20$ can $\% 20$ also $\% 20$ be $\% 20$ cast,for $\% 20$ some $\% 20$ heat $\% 2$ Dtreatable $\% 2$ 0alloys. 
Balakrishna, A., Rao, D., Srinivas, J. and Satish, P. (2007). Computer aided material selection processes in concurrent engineering using neural networks. Journal of the Institution of Engineers (India): Mechanical Engineering Division 88, 20-3.

Birtok-Băneasă, C., Rațiu, S., Puțan, V. and Zgripcea, L. (2019). Experimental studies regarding the influence of the intake manifold material on the thermodynamics processes in the internal combustion engines. Materials Science and Engineering, 477, https://doi.org/10.1088/1757899X/477/1/012006.

Bovea, M. and Vidal, R. (2004). Materials selection for sustainable product design: a case study of wood based furniture eco-design. Materials Desing, 25, 111-116. https://doi.org/10.1016/j.matdes.2003.09.018

Cebon, D. and Ashby, M. (2005). Data systems for optimal material selection. International Symposium on Materials Databases , 3-15. Tokyo, Japan.

Chandekar, A. and Debnath, B. (1 September 2020). Effect of intake manifold design on the mixing of air and bio-CNG in a port-injected dual fuel diesel engine. Journal of Thermal Analysis and Calorimetry, 2295-2309, https://doi.org/10.1007/s10973-020-09591-1.

Chen, X. and Jiang, G. (2008). Manufacturing of aluminum alloy air intake manifold by tilted casting. Special Casting and Nonferrous Alloys, 9, (28), 728-729, doi:10.3870/tzzz.2008.09.025.

Çetin, A. ve Sayer, S. (2019). Emme manifoldu üretiminde gelişen teknolojik uygulamalar. Mühendis ve Makina, 60, (696), 251-261.

Epsan, 2021. (http://epsan.com.tr/wpcontent/uploads/2019/10/epsan_teknik_katalogl ar.pdf).

Ferguson, C. R., and Kirkpatrick, A. T. (2001). Internal combustion engines: applied thermosciences. New York: John Wiley \& Sons.

Findık, F., Çolak, M. ve Aslanlar, S. (2015). Materials selection for car bumper with a conventional method as well as CES selector software. 1st International Conference on Engineering and Natural Sciences (ICENS 2015),199-208

Findık, F., Okumuş, S. C. ve Çolak, M. (2018). Malzeme seçimi ve uygulamaları. Seçkin Yayınevi.

Giudice, F., La, R. G. and Risitano, A. (2005). Materials selection in the life cycle design process: a method to integrate mechanical and environmental performances in optimal choice.
Materials\&Method,
26 ,
9-20. https://doi.org/10.1016/j.matdes.2004.04.006

Goldsberry, C. (2006). Design Focus: Computer modeling and how it helps drive material selection. Retrieved from Plastics Today. https://www.plasticstoday.com/design-focuscomputer-modeling-and-how-it-helps-drivematerial-selection.

Heywood, J. B. (1988). Internal combustion engine fundamentals. Singapore: McGraw-Hill.

Hickman, G. F. and Schumacher, D. (2005). Polyamide intake manifold shell bonding. SAE Intenational SAE World Congress, (Detroit, Michigan), https://doi.org/10.4271/2005-01-1518.

International Energy Agency. (2020, 11 26). Extended world energy balances (Edition 2020). https://doi.org/10.1787/88fd1acf-en.

Jain, A., Porpathamn, E. and Thipse, S. S. (2021). Numerical and simulation approach for design of variable valve actuation mechanism on singlecylinder diesel engine. Advances in IC Engines and Combustion Technology, 821-839. https://doi.org/10.1007/978-981-15-5996-9_63.

Jalham, I. (2006). Computer-aided quality function deployment method for material selection. Int J Comput Appl Technol,26, 190-196. https://doi.org/10.1504/IJCAT.2006.010764.

Kandemir, K. ve Can, A. Ç. (2003). Otomotiv endüstrisinde magnezyum alaşımlarının kullanım potansiyeli. Pamukkale Üniversitesi Mühendislik Fakültesi Mühendislik Bilimleri Dergisi, 1, (9), 37-45.

Karana, E., Hekkert, P. and Kandachar, P. (2008). Material considerations in product design: a survey on crucial material aspects used by product designers. Materials and Design, 10811089. https://doi.org/10.1016/j.matdes.2007.06.002.

Pulkraberk, W. W. (2016). İçten yanmalı motorlar mühendislik temelleri, İzmir: Güven.

Ramalhete, P., Senos, A. and Aguiar, C. (2010). Digital tools for material selection in product design. Materials and Design, 2275-22, https://doi.org/10.1016/j.matdes.2009.12.013.

Röchling

Automotive, 2021. (https://www.roechling.com/automotive/product s-solutions/propulsion/air-intake-manifoldsystems

Safgönül, B., Ergeneman, M., Arslan, E. ve Soruşbay, C. (2008). İçten yanmalı motorlar. İstanbul: Birsen Yayınevi. 
Sapuan, S. (2001). A knowledge-based system for materials selection in mechanical engineering design. Materials Design, 687-695, doi:10.1016/S0261-3069(00)00108-4.

Sapuan, S., Jacob, M., Mustapha, F. and Ismail, N. (2002). A prototype knowledge-based system for material selection of ceramic matrix composites of automotive engine components. Materials and Design, 2, 701-708, doi:10.1016/S02613069(02)00074-2.

Sensoy Abdullah Tahir, C. M. (2019). Optimal material selection for total hip implant: a finite element case study. Arabia Journal for Science and Engineering, https://doi.org/10.1007/s13369019-04088-y.
Shackelford, F. (2009). Introduction to materials science for engineers. London: Pearson.

Simav, O. ve Ustabaş, A. (2017). Otomotiv endüstrisindeki muhtemel dönüşümün ekonomik boyutu: Türkiye örneği. Internatıonal Conference On Eurasian Economies 2017, 310319, İstanbul.

UNFCCC. (2020, 11 30). Retrieved from what is the Kyoto Prtocol. https://unfecc.int/kyoto_protocol

Vijaya Kumar, K., Shailesh, P., Srinivasa Raghavan, K., Ranga Babu, J. and Ravi Kumar, P. (2020). Performance and emission analysis of diesel engine with design modifications on piston crown. International Journal of Ambient Energy, 41 , $1336-1341$ https://doi.org/10.1080/01430750.2018.1517664 